\title{
Indoor characterisation of a reverse truncated pyramid concentrator.
}

\author{
TAMUNO-IBUOMI, L.O., MUHAMMAD-SUKKI, F., RAMIREZ-INIGUEZ, R., \\ ARDILA-REY, J.A., ABU-BAKAR, S.H., BANI, N.A., SEE, C.H., FAISAL, N.H. \\ and SELLAMI, $\mathrm{N}$.
}

The conference paper (pages 2-4) is distributed under the following terms. (C) 2021 IEEE. Personal use of this material is permitted. Permission from IEEE must be obtained for all other uses, in any current or future media, including reprinting/republishing this material for advertising or promotional purposes, creating new collective works, for resale or redistribution to servers or lists, or reuse of any copyrighted component of this work in other works.

The poster included in this file (page 5) is distributed under Creative Commons Attribution-Non Commercial 4.0 International Public License (https://creativecommons.org/licenses/by-nc/4.0/). 


\title{
Indoor Characterisation of a Reverse Truncated Pyramid Concentrator
}

\author{
Lewis Osikibo Tamuno-Ibuomi ${ }^{1}$, Firdaus Muhammad-Sukki ${ }^{2, *}$, Roberto Ramirez-Iniguez ${ }^{1}$, \\ Jorge Alfredo Ardila-Rey ${ }^{3}$, Siti Hawa Abu-Bakar ${ }^{4}$, Nurul Aini Bani ${ }^{5}$, Chan Hwang See ${ }^{2}$, \\ Nadimul Haque Faisal ${ }^{6}$ and Nazmi Sellami ${ }^{6}$
}

\author{
${ }^{1}$ School of Computing, Engineering and Built Environment, Glasgow Caledonian University, 70 \\ Cowcaddens Road, Glasgow, G4 0BA, United Kingdom \\ ${ }^{2}$ School of Engineering \& the Built Environment, Edinburgh Napier University, Merchiston Campus, 10 \\ Colinton Road, Edinburgh EH10 5DT, United Kingdom \\ ${ }^{3}$ Department of Electrical Engineering, Universidad Técnica Federico Santa María, Santiago de Chile \\ 8940000, Chile \\ ${ }^{4}$ Renewable Energy Research Laboratory; Electrical Engineering Section, British Malaysian Institute, \\ Universiti Kuala Lumpur, Jalan Sungai Pusu, Selangor 53100, Malaysia \\ ${ }^{5}$ Razak Faculty of Technology and Informatics, Universiti Teknologi Malaysia, Jalan Sultan Yahya Petra, \\ Kuala Lumpur 54100, Malaysia \\ ${ }^{6}$ School of Engineering, Robert Gordon University, The Sir Ian Wood Building, Garthdee Road, AB10 7GJ \\ Aberdeen, United Kingdom
}

*Corresponding author: f.muhammadsukki@ napier.ac.uk

\begin{abstract}
The development of concentrating photovoltaic (PV) started in 1960s and over the years, a variety of concentrator designs have been explored. One of its applications is for use in building integrated photovoltaic (BIPV) with the aim of producing a cheaper alternative to a traditional PV panel. This paper presents the experimental characterization of a low concentrating photovoltaic (LCPV) unit that utilizes a reverse truncated pyramid (RTP) concentrator design. The RTP has a geometrical gain of 3.61 and a total height of $40 \mathrm{~mm}$. The result from indoor characterization shows that the RTP-PV device could achieve an opto-electronic gain of 3.0 with a measured half-acceptance angle of $\pm 23.8^{\circ}$. The RTP-PV can be used as a suitable alternative to traditional solar PV panels.
\end{abstract}

Keywords-photovoltaic, reverse truncated pyramid, indoor characterization.

\section{INTRODUCTION}

Solar photovoltaic (PV) application to buildings in urban settlements began long ago, far back as 1970s and has since then, remained a viable research space especially in this era of modern energy-harvesting technology for buildings [1]. This application transforms the energy-efficient buildings from consumers of energy into producers of energy, and the technologies which enhance the integration of solar PV into the building structure are called building applied photovoltaic (BAPV) and building integrated photovoltaic (BIPV). In BAPV application, the PV materials do not replace any part of the building but are mounted on the roofs or facades while in the BIPV system, the PV materials directly replace parts of the conventional building structure like the facades, windows and roofs [2].

The challenge with BAPV and BIPV is the perceived high cost of installation which has made their wide adoption difficult hence, domiciled in urban settings [3]. Primarily, the high installation cost of the solar PV modules has been attributed mainly to the material cost according to some researchers [4]. To remove the cost equation from the costly BIPV materials, researchers have proposed the inclusion of a cheap solar concentrator to the PV module in order to improve its performance and reduce the volume of PV materials. This technology of introducing an optical or solar concentrator into the PV module or cell is called concentrated photovoltaic (CPV) [5].

The CPV is an optical device which redirects incident sunlight from a wider entrance aperture and reflects it to a smaller exit aperture where a solar cell is attached. This increases light intensity and illumination on the solar cell and in turn, increasing its electrical output. The integration of the CPV modules into buildings is known as building integrated concentrating photovoltaic (BICPV) technology. This is more economical, cost effective, more flexible, more efficient and easier to maintain when compared to BAPV and BIPV systems but yet to compete commercially [6].

This paper presents the experimental characterization of a low concentrating photovoltaic (LCPV) unit that utilizes a reverse truncated pyramid (RTP) concentrator design. The 
indoor characterization evaluates the RTP-PV electrical characteristics and its angular response.

\section{RTP CONCENTRATOR}

Fig. 1 shows the RTP-PV device. It consists of a truncated reversed pyramid concentrator made from BK7 glass, a triple junction solar cell and a bypass diode. The physical dimensions of the RTP concentrator are presented in Table 1.

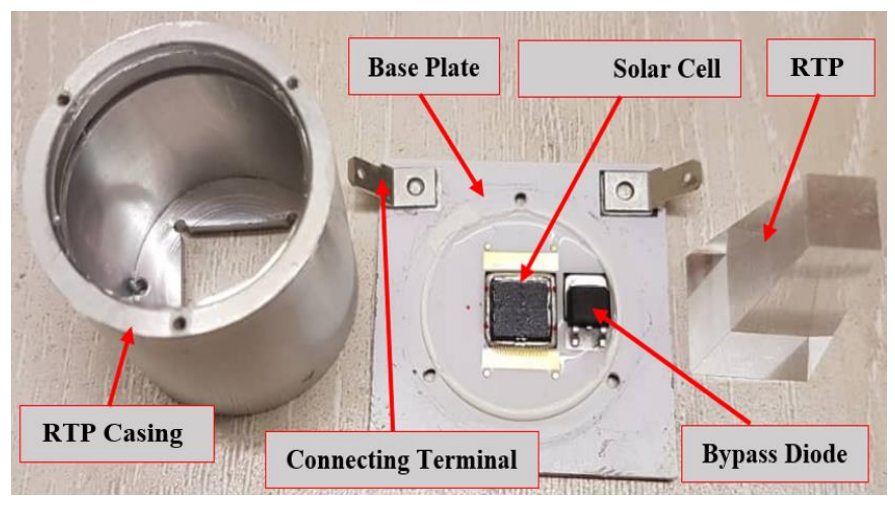

Fig. 1. Components of CPV.

TABLE 1. Parameters of the RTP Concentrator

\begin{tabular}{|c|c|c|}
\hline Parameter & Value & Unit \\
\hline Concentrator height & 40 & $\mathrm{~mm}$ \\
\hline Entrance aperture length & 19 & $\mathrm{~mm}$ \\
\hline Exit aperture length & 10 & $\mathrm{~mm}$ \\
\hline Entrance aperture Area & 361 & $\mathrm{~mm}^{2}$ \\
\hline Exit aperture Area & 100 & $\mathrm{~mm}^{2}$ \\
\hline Geometrical concentration ratio & 3.61 & \\
\hline
\end{tabular}

\section{EXPERIMETAL SETUP}

The experiments were conducted indoors in Glasgow Caledonian University's laboratory facility. The experimental setup is presented in Fig. 2. It includes an Oriel Sol3 $\mathrm{A}^{\mathrm{TM}}$ Class AAA solar simulator (model 94083A) from Newport Corporation, which provided the needed illumination for the indoor experiments, with an irradiance of $1000 \mathrm{~W} / \mathrm{m}^{2}$. A source meter, 24405 A from Keithley Instruments was connected to a computer containing the software package LabTracer 2.0. A reference PV cell with a thermocouple was provided which was used to set the irradiance at standard test conditions (STCs) and measure the room temperature. The solar simulator can be tuned to produce various irradiance levels. A platform for changing the angle of incident of the solar concentrator was also provided called variable slope base. The angular slope of the concentrator is measured with a digital level meter calibrated in degrees.

F.M.-S, SH.A.-B, N.A.B and C.H.S. acknowledged the fund from Edinburgh Napier University under the Strategic Research \& Knowledge Exchange Fund 2020/21 (Project No: 2750286). F.M.-S, N.H.F and N.S thanked Robert Gordon University for funding the work under pump priming 'METACOAT' project (No. 232073). L.O.T.-I. and R.R.-I. acknowledged Glasgow Caledonian University for providing access to the testing facility. J.A.A.-R. thanked Agencia Nacional de Investigación y Desarrollo (ANID) for the support received through the projects Fondecyt regular 1200055 and Fondef ID19I10165 and the UTFSM for the project PI_m_19_01 for funding the IEEE PVSC conference fee.

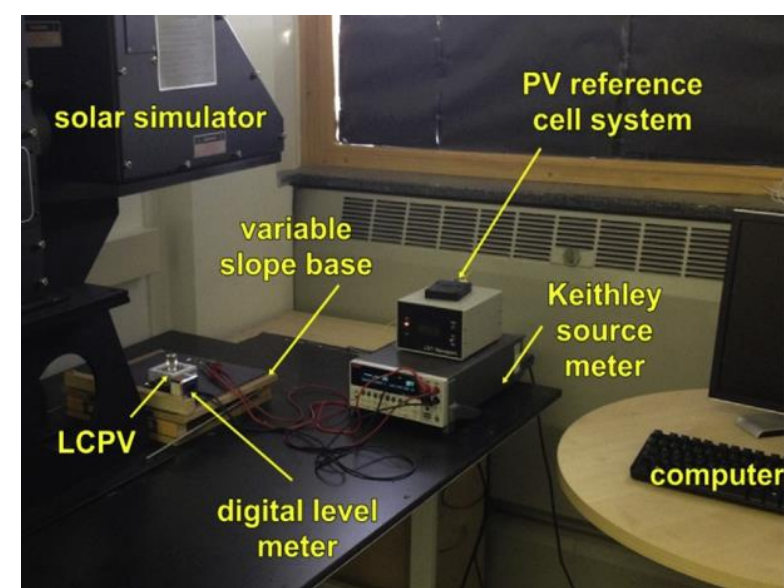

Fig. 2. Indoor experimental setup for RTP-PV characterization.

\section{RESUlTS AND DisCUSSIONS}

\section{A. Current-voltage $(I-V)$ and power-voltage $(P-V)$} characteristics

The current-voltage (I-V) and power-voltage (P-V) characteristics of the RTP-PV device and the non-concentrating PV cell is shown in Fig. 3. The results show that RTP increased the short-circuit current (Isc) of the bare cell from $13.05 \mathrm{~mA}$ to $40.6 \mathrm{~mA}$, the open-circuit voltage (Voc) from $2.6 \mathrm{~V}$ to $2.7 \mathrm{~V}$, the maximum power output from $29.3 \mathrm{~mW}$ to $95.85 \mathrm{~mW}$, and the fill-factor from 0.864 to 0.874 at STCs. This gives a power gain of about 3.3, indicating an improved performance.

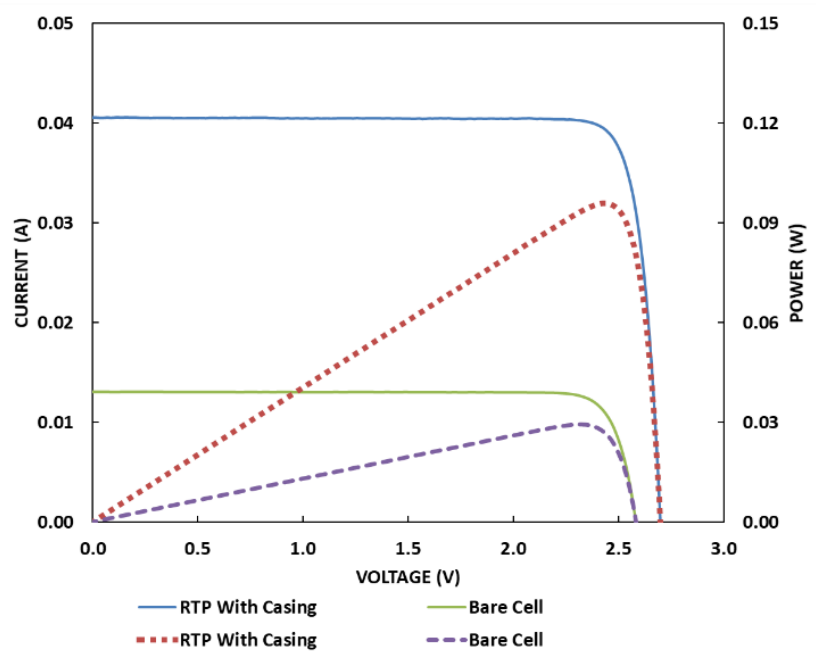

Fig. 3. The current-voltage (I-V) (in solid lines) and power-voltage (P-V) (in dotted lines) characteristics of the RTP-PV device and the non-concentrating PV cell at STCs.

\section{B. Variations in irriadiance}

The response of the RTP was tested at different flux values as shown in Fig. 4. The results show that as the irradiance was 
increased steadily, the maximum power increased accordingly. This is typical of solar PV cells [4].

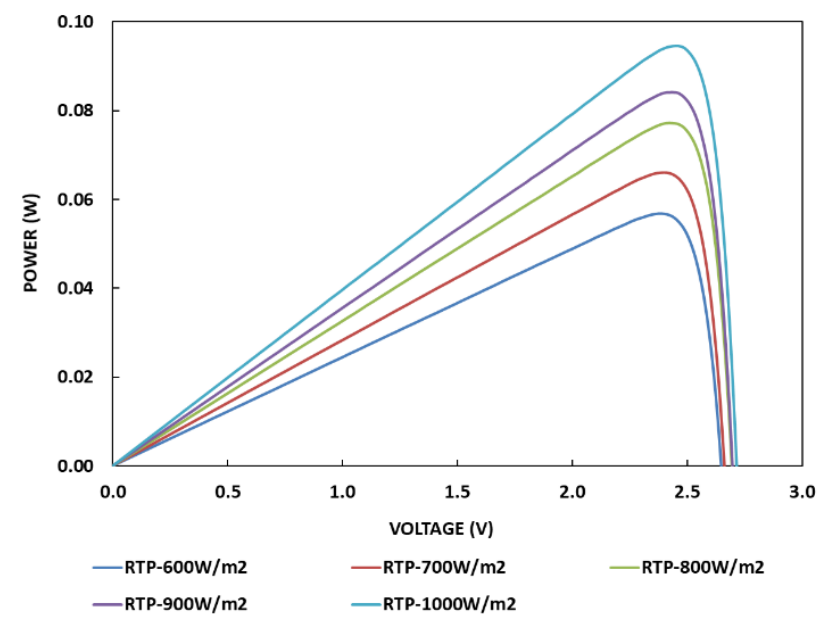

Fig. 4. The maximum power output of the RTP-PV at various irradiances.

\section{Angular response of the RTP-PV device}

Fig. 5 gives the result of the angular response of the RTPPV concentrator. It shows that the RTP can increase the electrical output by a factor of about 3.0 when compared to the non-concentrating cell. Also, from the angular performance of the CTRP, it shows that the half-acceptance angle is $\pm 23.8^{\circ}$.

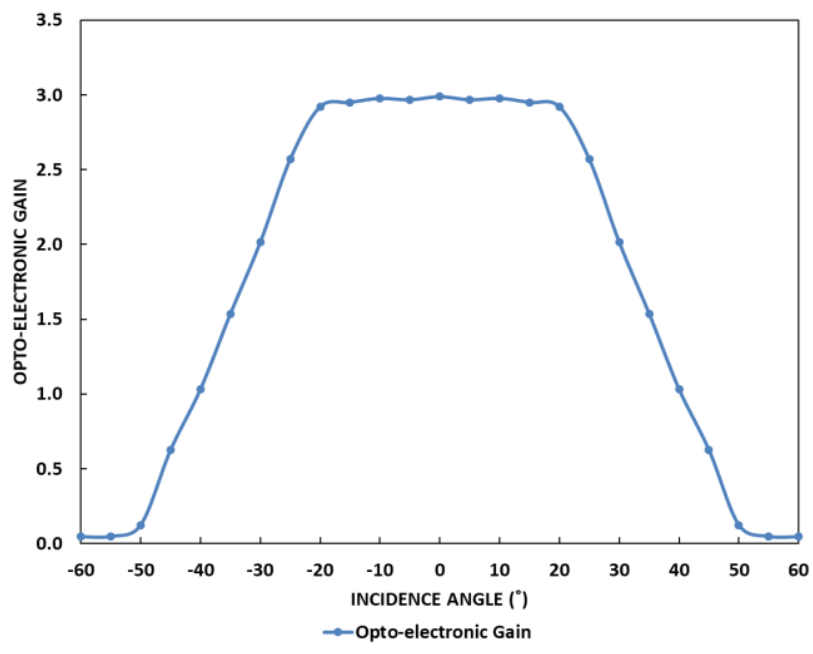

Fig. 5. The angular response of the RTP-PV device.

\section{CONCLUSIONS}

The characterization of an LCPV that employs an RTP concentrator was carried out. The RTP concentrator, which has a geometrical concentration ratio of $3.61 \mathrm{x}$, was investigated. It was found that the device could achieve an opto-electronic gain of 3.0 and has a measured half-acceptance angle of $\pm 23.8^{\circ}$. The RTP-PV can be used as an alternative to a traditional solar PV panel. The next step would be to study create a small solar window incorporating these RTP concentrators, integrate the CPV window into a building structure, and test its electrical performance.

\section{REFERENCES}

[1] N. Sellami and T. K. Mallick, "Optical characterisation and optimisation of a static Window Integrated Concentrating Photovoltaic system," Sol. Energy, vol. 91, pp. 273-282, May 2013.

[2] N. M. Kumar, K. Sudhakar, and M. Samykano, "Performance comparison of BAPV and BIPV systems with c-Si, CIS and CdTe photovoltaic technologies under tropical weather conditions," Case Stud. Therm. Eng., vol. 13, p. 100374, Mar. 2019.

[3] R. Ramirez-Iniguez, J. Deciga-Gusi, D. Freier, S. H. Abu-Bakar, and F. Muhammad-Sukki, "Experimental evaluation of a solar window incorporating rotationally asymmetrical compound parabolic concentrators (RACPC)," Energy Procedia, vol. 130, pp. 102-107, Sep. 2017.

[4] S. H. Abu-Bakar et al., "Performance analysis of a solar window incorporating a novel rotationally asymmetrical concentrator," Energy, vol. 99, pp. 181-192, Mar. 2016.

[5] Y. Amanlou, T. T. Hashjin, B. Ghobadian, G. Najafi, and R. Mamat, "A comprehensive review of Uniform Solar Illumination at Low Concentration Photovoltaic (LCPV) Systems," Renew. Sustain. Energy Rev., vol. 60, pp. 1430-1441, 2016.

[6] X. Meng et al., "A novel absorptive/reflective solar concentrator for heat and electricity generation: An optical and thermal analysis," Energy Convers. Manag., vol. 114, pp. 142-153, 2016. 
Lewis Osikibo Tamuno-lbuomi' ${ }^{1}$, Firdaus Muhammad-Sukki ${ }^{2,}{ }^{*}$, Roberto Ramirez-Iniguez ${ }^{1}$, Jorge Alfredo Ardila-Rey ${ }^{3}$, Siti Hawa Abu-Bakar ${ }^{4}$, Nurul Aini Bani ${ }^{5}$, Chan Hwang See ${ }^{2}$,

Nadimul Haque Faisal ${ }^{6}$ and Nazmi Sellami ${ }^{6}$

${ }^{1}$ Glasgow Caledonian University, 70 Cowcaddens Road, Glasgow, G4 OBA, UK

2 Edinburgh Napier University, Merchiston Campus, 10 Colinton Road, Edinburgh EH10 5DT, UK

${ }^{3}$ Universidad Técnica Federico Santa María, Santiago de Chile, 8940000, Chile

4 Universiti Kuala Lumpur, Jalan Sungai Pusu, Selangor 53100, Malaysia

5 Universiti Teknologi Malaysia, Jalan Sultan Yahya Petra, Kuala Lumpur 54100, Malaysia

${ }^{6}$ Robert Gordon University, Garthdee Road, Aberdeen, AB10 7GJ, UK

Email: f.muhammadsukki@napier.ac.uk

GCU

Glasgow Caledonian

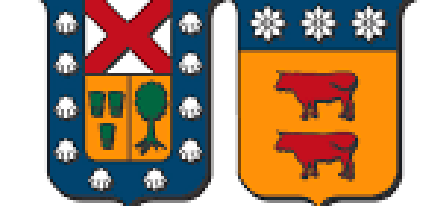

UNIVERSIDAD TECNICA

(1)

Uni KL

UNIVERSITI

(3) UTM

\section{Introduction}

Solar photovoltaic (PV) application to buildings in urban settlements began long ago, far back as 1970s and has since then, remained a viable research space especially in this era of modern energyharvesting technology for buildings [1]. This application transforms the energy-efficient buildings from consumers of energy into producers of energy, and the technologies which enhance the integration of solar PV into the building structure are called building applied photovoltaic (BAPV) and building integrated photovoltaic (BIPV). In BAPV application, the PV materials do not replace any part of the building but are mounted on the roofs or facades while in the BIPV system, the PV materials directly replace parts of the conventional building structure like the facades, windows and roofs [2].

The challenge with BAPV and BIPV is the perceived high cost of installation which has made their wide adoption difficult hence, domiciled in urban settings [3]. Primarily, the high installation cost of the solar PV modules has been attributed mainly to the material cost according to some researchers [4]. To remove the cost equation from the costly BIPV materials, researchers have proposed the inclusion of a cheap solar concentrator to the PV module in order to improve its performance and reduce the volume of PV materials. This technology o cell is called concentrated photovoltaic (CPV) [5].

\section{Research Objectives}

This paper presents the experimental characterization of a low concentrating photovoltaic (LCPV) unit hat utilizes a reverse truncated pyramid (RTP) concentrator design (Fig. 1). The indoor characterization evaluates the RTP-PV electrical characteristics and its angular response.

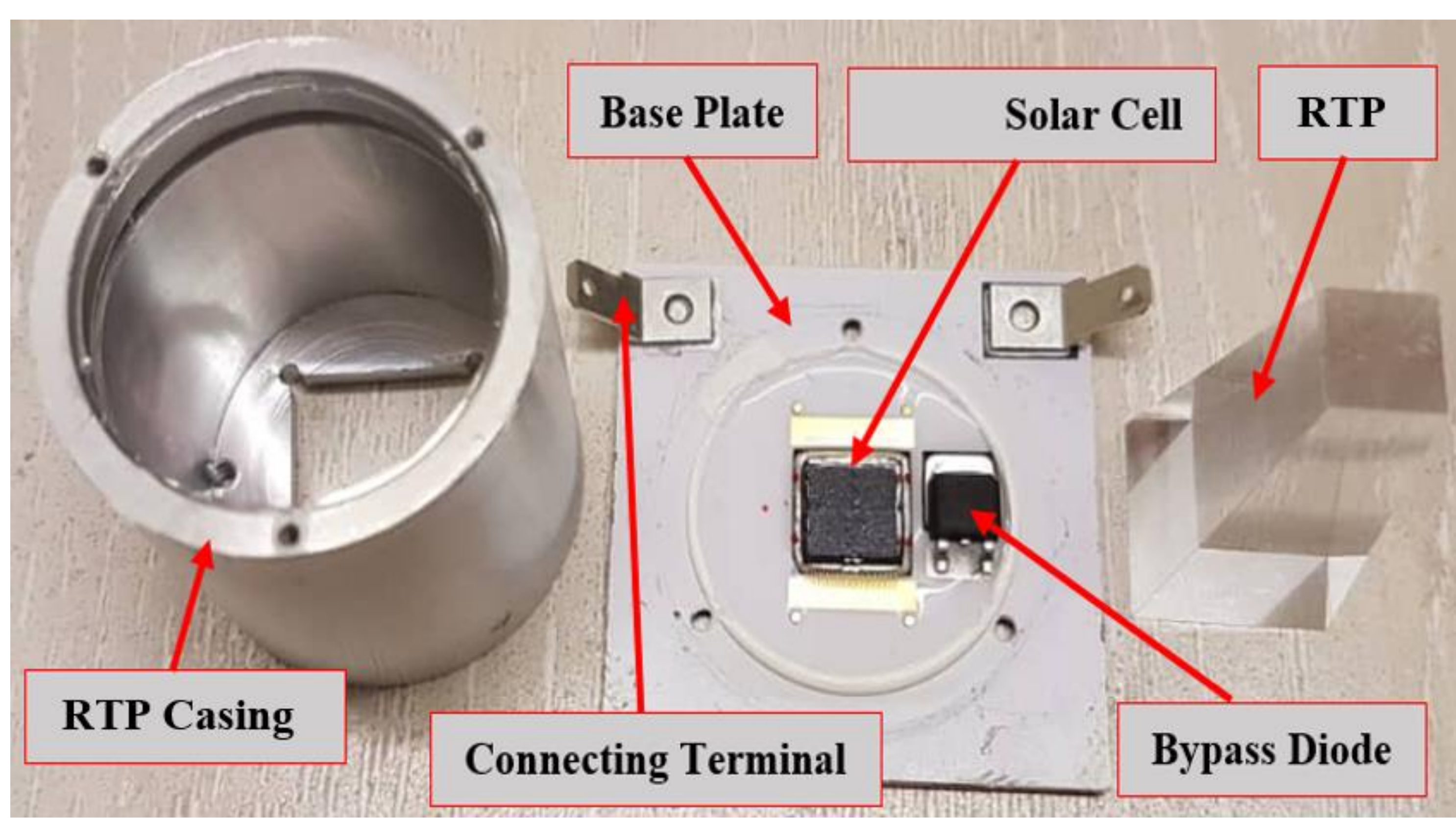

Fig.1. Components of CPV

\section{Experimental Setup}

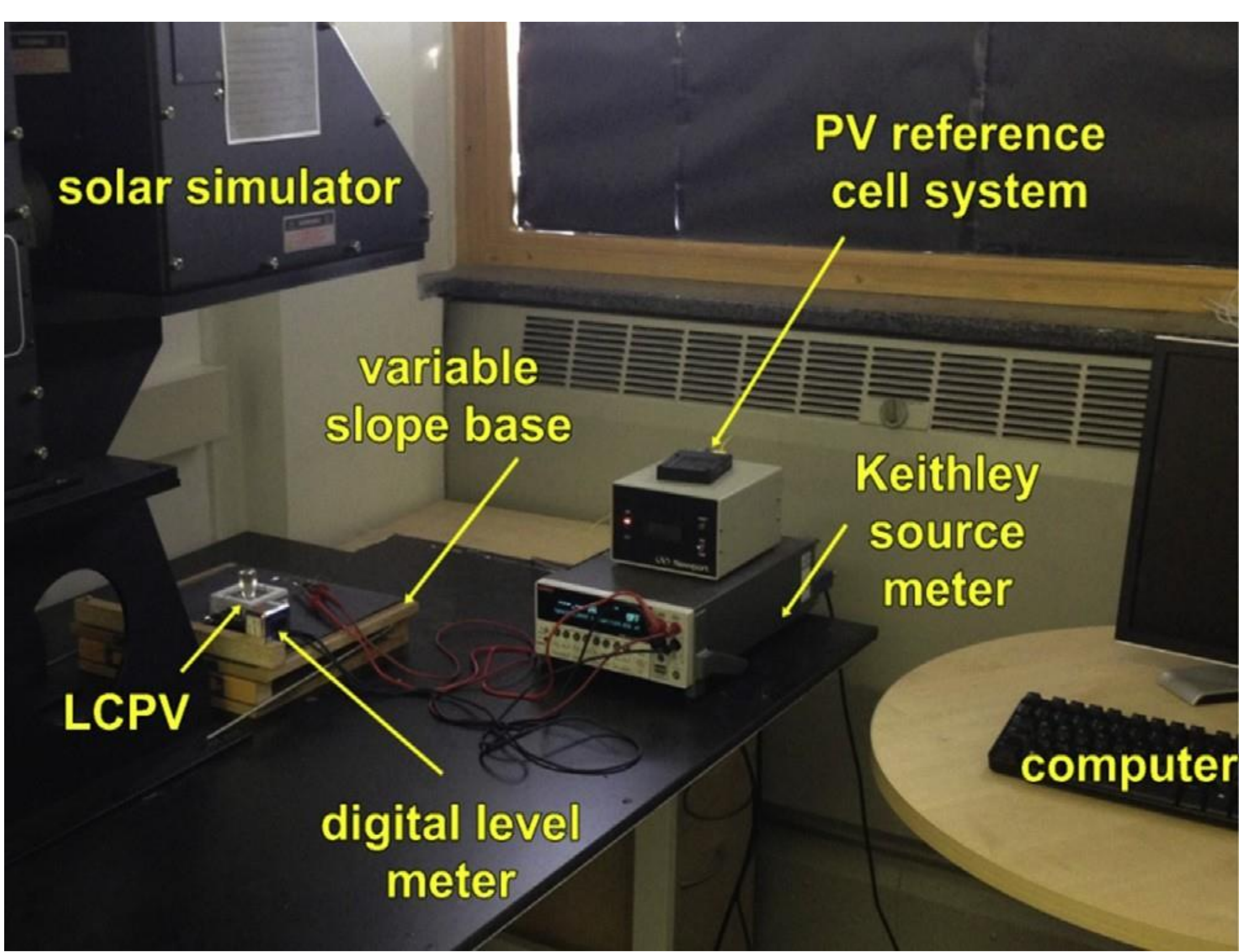

Fig.2. Indoor experimental setup

The experiments were conducted indoors in Glasgow Caledonian University's laboratory facility. The experimental setup is presented in Fig. 2. It includes an Oriel Sol3A ${ }^{\mathrm{TM}}$ Class AAA solar simulator (model 4083A) from Newport Corporation, which provided the needed illumination for the indoor experiments, with an irradiance of $1000 \mathrm{~W} / \mathrm{m} 2$. A source meter, $24405 \mathrm{~A}$ from Keithley Instruments was connected to a computer containing the software package LabTracer 2.0. A reference PV cell with a thermocouple was provided which was used to set the irradiance at standard test conditions (STCs) and measure the room temperature. The solar simulator can be tuned to produce various irradiance levels. A platform for changing the angle of incident of the solar concentrator was also provided called variable slope base. The angular slope of the concentrator is measured by a digital level meter calibrated in degrees..

\section{References}

1] Sellami \& Mallick, Sol. Energy 2013;91:273-282. [2] Kumar et al., Case Stud. Therm. Eng. 2019;13:100374. [3] Ramirez-Iniguez et al., Energy Procedia 2017:130:102-107. [4] Abu-Bakar et al. Energy 2016;99:181-192. [5] Amanlou et al., Renew. Sustain. Energy Rev. 2016;60:1430-1441.

\section{Result}

A. Current-voltage $(\mathrm{I}-\mathrm{V})$ and power-voltage $(\mathrm{P}-\mathrm{V})$ characteristics

The current-voltage $(I-V)$ and power-voltage (P-V) characteristics of the RTP-PV device and the nonconcentrating PV cell is shown in Fig 3 . The results show that RTP increased the short-circuit current (Isc) of the bare cell from $13.05 \mathrm{~mA}$ to $40.6 \mathrm{~mA}$, the open-circuit voltage (Voc) from $2.6 \mathrm{~V}$ to $2.7 \mathrm{~V}$, the maximum power output from $29.3 \mathrm{~mW}$ to $95.85 \mathrm{~mW}$, and the fill-factor from 0.864 to 0.874 at STCs. This gives a power gain of about 3.3, indicating an improved performance.

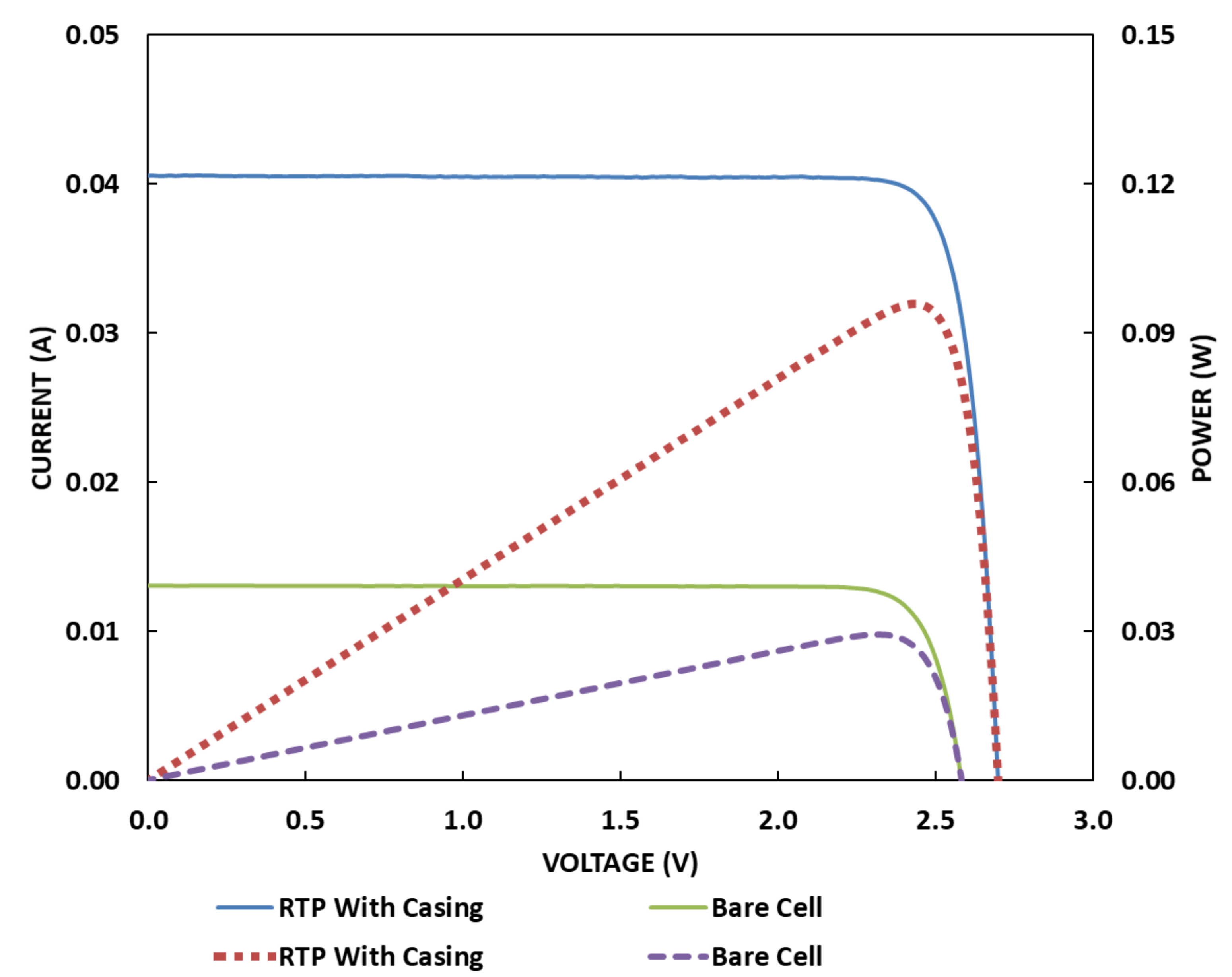

Fig 3. I-V curves of the RTP-PV under STCs

B. Angular response of the RTP-PV device

Fig. 4 gives the result of the angular response of the RTP-PV concentrator. It shows that the RTP can increase the electrical output by a factor of about 3.0 when compared to the non-concentrating cell. Also, from the angular performance of the CTRP, it shows that the half-acceptance angle is $\pm 23.8^{\circ}$.

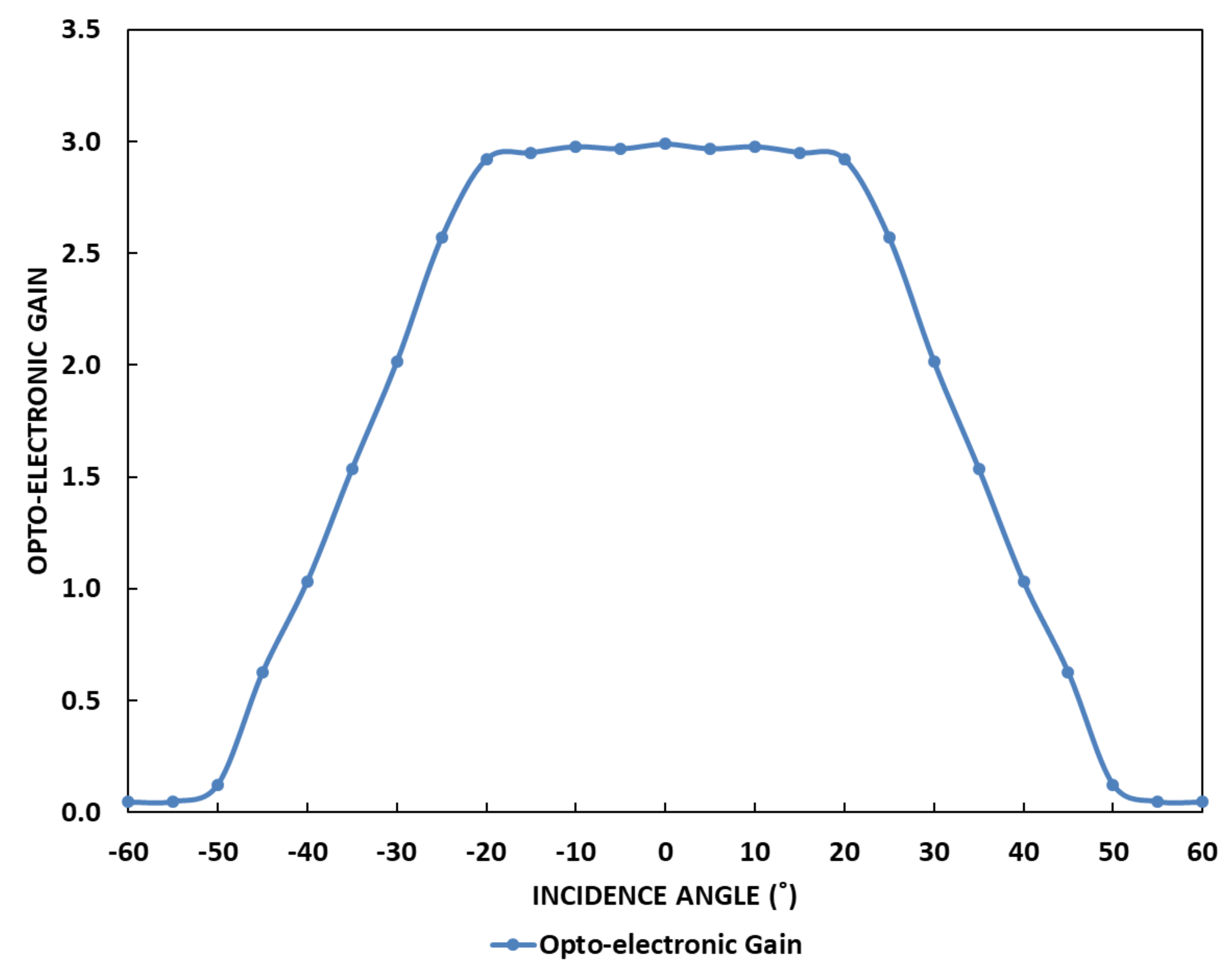

Fig 4. The angular response of the RTP-PV device

\section{Conclusion}

The characterization of an LCPV that employs an RTP concentrator was carried out. The RTP concentrator, which has a geometrical concentration ratio of $3.61 \mathrm{x}$, was investigated. It was found that the device could achieve an opto-electronic gain of 3.0 and with a measured half-acceptance angle of $\pm 23.8^{\circ}$. The RTP-PV can be used as an alternative to a traditional solar PV panel.

\section{Acknowledgements}

F.M.-S, SH.A.-B, N.A.B and C.H.S. acknowledged the fund from Edinburgh Napier University under the Strategic Research \& Knowledge Exchange Fund 2020/21 (Project No: 2750286). F.M.-S, N.H.F and N.S thanked Robert Gordon University for funding the work under pump priming 'METACOAT' project (No. 232073) . L.O.T.-I. and R.R.-I. acknowledged Glasgow Caledonian University for providing access to the testing facility. J.A.A.-R. thanked Agencia Nacional de Investigación y Desarrollo (ANID) for the support received through the projects Fondecyt regular 1200055 and Fonde ID19I10165 and the UTFSM for the project PI $m_{1} 1901$ for funding the IEEE PVSC conference fee. 